\title{
THE INFLUENCE OF DIFFERENT SPECIES OF YEAST ON MYCOTOXINS CONCENTRATIONS IN WHEAT
}

Gintarė VAIČIULIENĖ, Department of Food Safety and Quality, Faculty of Veterinary, Veterinary Academy of Lithuanian University of Health Sciences, A. Mickevičiaus str. 9, LT-44307, Kaunas, Lithuania, gintare.vaiciuliene@1smu.lt (corresponding author)

Algimantas PAŠKEVIČIUS, Institute of Botany of Nature Research centre, Biodeterioration Research Laboratory, Akademijos str. 2, LT-08412, Vilnius, Lithuania, algimantas.paskevicius@gamtc.lt

Laura KNIZIKEVIČIŪTÉ, Department of Food Safety and Quality, Faculty of Veterinary, Veterinary Academy of Lithuanian University of Health Sciences, A. Mickevičiaus str. 9, LT-44307, Kaunas, Lithuania, 11llaura.k@gmail.com

Gediminas GERULIS, Department of Food Safety and Quality, Faculty of Veterinary, Veterinary Academy of Lithuanian University of Health Sciences, A. Mickevičiaus str. 9, LT-44307, Kaunas, Lithuania, gediminas.gerulis@1smuni.lt

The aim of this study was to evaluate the effect of Saccharomyes cerevisiae, Geotrichum fermentans, Rhodotorula rubra and Kluyveromyces marxianus yeast cell suspensions and Saccharomyces cerevisiae cell wall's polysaccharides and fermentation time on mycotoxins concentrations in feed wheat. The 2018 harvest three feed wheat samples were taken from grain processing companies, and the research was carried out at the Lithuanian University of Health Sciences, Veterinary Academy, Mycotoxicology Laboratory. The Thin-layer chromatography technique (TLC) was used to determine mycotoxins concentrations in the samples. The wheat samples were inoculated with Saccharomyces cerevisiae, Geotrichum fermentans Rhodotorula rubra and Kluyveromyces marxianus yeast $10^{4}$ cells $\mathrm{ml}^{-1}$ suspensions and Saccharomyces cerevisiae cell wall`s polysaccharides, duration of the wheat fermentation with the yeast were -30 and $60 \mathrm{~min}$. It was found that all yeast species suspensions had reducing effect of mycotoxins concentrations which correlated with longer duration of fermentation. Saccharomyces cerevisiae yeast suspension after 60 min reduced $\mathrm{AFB}_{1}$ and DON by $100 \%(\mathrm{p}<0.05)$ and ZEA up to $80.1 \pm 0.50 \%$ ( $\left.<<0.05\right)$. Saccharomyces cerevisiae yeast cell wall`s polysaccharides decreased the concentrations of AFB1 ( $p>0.05)$, ZEA ( $<<0.05), D O N(p<0.05)$ during the experiment better than Saccharomyces cerevisiae $10^{4}$ cells $\mathrm{ml}^{-1}$ suspension and after 60 min exposure polysaccharides absorbed all wheat mycotoxins by $100 \%$ ( $\mathrm{p}<0.05$ ). The AFB1 was best absorbed by Kluyveromyces marxianus yeast after 60 min. of fermentation by $100 \%(\mathrm{p}<0.05)$. The DON concentration was below the detection limit after 60 min. of fermentation with Geotrichum fermentans and Rhodotorula rubra yeast.

Keywords: fermentation, mycotoxins, wheat, yeast, yeast cell wall's polysaccharides

\section{INTRODUCTION}

Wheat is one of the primary grain culture cultivated in Lithuania and the world. According to United Nations Food and Agriculture Organization statistics, world food and feed production use 141 to 510 million tonnes of wheat per year (FAO Food outlook..., 2019).

The quality of wheat is mostly affected by contamination by Fusarium spp., Aspergillus spp. and Penicillium spp. mould fungi and their secondary metabolites - mycotoxins (Beukes et al., 2018). Aflatoxin B1 (AFB1), deoxynivalenol (DON), zearalenone (ZEA) and T-2 toxin - are dominant mycotoxins in wheat and their products (Mankevičienè et al., 2011; Asghar et al., 2016). Mycotoxins which are found in wheat easily can pass to animals feed and people food (Bol et al., 2016; Stanciu et al., 2017). Mycotoxins in feed can cause growth disturbances in the animal's body, reduces the body's growth capacity, nutrient uptake, cause changes in genetic systems - disruption of gene activity associated with the transport of nutrients, possible cellular oxidative damage (Wu et al., 2015).

After evaluating the contamination of feed wheat by mycotoxins, biological detoxification is increasingly used. Yeast can be chosen for this purpose because the morphological structure of the polysaccharides and especially, the $\beta$ D - glucans, which are found in the yeast cell wall' s, have mycotoxins absorbing effect (Aazami et al., 2018). In addition, to the food Saccharomyces cerevisiae yeast used in the food and agriculture industry, other species may also reduce mycotoxins in wheat, for example such as - Geotrichum fermentans, Rhodotorula rubra, and Kluyveromyces marxianus (Repečkienè et al., 2013).

The aim of this study was to evaluate the effect of Saccharomyes cerevisiae, Geotrichum fermentans, Rhodotorula rubra and Kluyveromyces marxianus yeast cell suspensions and Saccharomyces cerevisiae cell wall's polysaccharides and fermentation time on mycotoxins concentrations in feed wheat.

Copyright (C) 2019 The Authors. Published by Vytautas Magnus University. This is an open-access article distributed under the terms of the Creative Commons Attribution License (CC BY 4.0), which permits unrestricted use, distribution, and reproduction in any medium, provided the original author and source are credited. 


\section{MATERIAL AND METHODS}

In 2018 during September - December, 2018 year harvest wheat samples (three replicates) were collected from grains processing companies. In the Mycotoxicology Laboratory of Veterinary Academy of Lithuanian University of Health Sciences has carried out mycotoxins analysis and biological detoxification of wheat with food yeast Saccharomyces cerevisiae and their cell wall's polysaccharides and also with Geotrichum fermentans, Rhodotorula rubra, Kluyveromyces marxianus yeast, which was extracted from various vegetable substrates.

Determination of mycotoxins concentrations. In wheat samples AFB1, ZEA concentrations were analyzed by Thinlayer chromatography (TLC) and described by Romer Labs Inc. ${ }^{\circledR}$ Method (Austria) (Code: a/z-tl-01-00.2) and deoxynivalenol (DON) (Code: CAM-000031-1). For AFB1 and ZEA concentrations, silica gel (SG) plates were air-dried, and the results were evaluated on a ultraviolet (UV) background $(360 \mathrm{~nm})$. For DON concentration determination the SG plate was heated at $150^{\circ} \mathrm{C}$ for $5 \mathrm{~min}$ and $360 \mathrm{~nm}$ UV background was chosen. The detection limit of DON and ZEA is 10 $\mu \mathrm{g} / \mathrm{kg}$ and AFB1 - $1 \mu \mathrm{g} / \mathrm{kg}$ (Razzazi-Fazeli et al., 2002).

Yeast suspension production and inoculation of wheat. The yeast culture of Saccharomyces cerevisiae obtained from pressed baking yeast, while Geotrichum fermentans, Rhodotorula rubra and Kluyveromyces marxianus yeast were extracted from various vegetable substrates (corn, vegetables, fruits) and confirmed by PGR in the Institute of Botany of Nature Research centre, Biodeterioration Research Laboratory, Vilnius, Lithuania. Yeast cultures were multiplied by dilutions up to $10^{-6}$ and inoculated on Sabouraud Dextrose Agar (OXOID, UK) (SDA) surface. After 7 days of incubation in a thermostat at $28 \pm 2{ }^{\circ} \mathrm{C}$, the culture inoculated on a SDA following Samson et al. (1988) and incubated for 4 days at $28 \pm 2{ }^{\circ} \mathrm{C}$. For inoculum production, the yeast cell density is calculated using a Neubauer improved bright-line hemocytometer (Germany) of $0.100 \mathrm{~mm}\left(0.0025 \mathrm{~mm}^{2}\right)$. Yeast

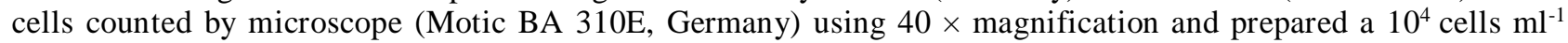
suspension in vitro, three feed wheat samples were inoculated based on Bakutis et al. (2005) modified method. During the research wheat samples $(15 \mathrm{~g})$ were grounded, moistened with $3 \mathrm{ml}$ of sterile water and treated with 1.5 $\mathrm{ml}$ of yeast (respectively Saccharomyces cerevisiae, Geotrichum fermentans, Rhodotorula rubra and Kluyveromyces marxianus) $10^{4}$ cells $\mathrm{ml}^{-1}$ suspensions. The fermentation was carried out at $28 \pm 2{ }^{\circ} \mathrm{C}$ for 30 and 60 min. Experiments were repeated three times.

Isolation of polysaccharides from the cell walls of Saccharomyces cerevisiae. The Saccharomyces cerevisiae yeast cell walls were destroyed based on Dallies et al. (1998) modified methods. For the isolation of polysaccharides, $20 \mathrm{mg}$ wet weight of Saccharomyces cerevisiae was mixed with $0.5 \mathrm{ml} 2^{\circ} \mathrm{C}$ Tris hydrochloride $(\mathrm{Tris}-\mathrm{HCl})(10 \mathrm{mM}$, $\mathrm{pH} 8)$. Sterile glass beads $(0.5 \mathrm{~g}, 0.45-0.55 \mathrm{~mm}$ in diameter) were used to break down the yeast cell wall' $\mathrm{s}$. Test-tube in which were Saccharomyces cerevisiae yeast with Tris- $\mathrm{HCl}$ buffer and glass beads were shaken in a V-1 Plus shaker with ice (BioSan, Latvia) $3000 \mathrm{rpm}$ at 4 times 20 following seconds, break time - $1 \mathrm{~min}$. After 4 shaking intervals, the percentage of cell walls destroy is assessed by microscopy using a $0.100 \mathrm{~mm}\left(0.0025 \mathrm{~mm}^{2}\right)$ Neubauer improved brightline hemocytometer. The reconstituted suspension was transferred to a sterile tube, then the glass beads were washed with $1 \mathrm{ml}$ Tris- $\mathrm{HCl}$ buffer solution cooled to $2^{\circ} \mathrm{C}$, and the resulting liquid phase was suction from the beads and placed in a standard tube, which is prepared for centrifugation for 5 min $1500 \mathrm{rpm}$ (Eppendorf 5810R, Germany). The only transparent surface liquid was used for the research (Dallies et al., 1998). Polysaccharide treatment of wheat samples were analogous to suspension processing. The experiment repeated three times.

Statistical analyses. The data analysed by SPSS statistical package (SPSS for Windows 17.0, SPSS Inc., Chicago, IL, USA, 2008) by 1-way analysis of variance (ANOVA). The results were considered to be reliable under $\mathrm{P}<0.05$.

\section{RESULTS}

The results of this study indicate that Saccharomyces cerevisiae yeast and their cell wall's polysaccharides and from various vegetable substrates extracted Geotrichum fermentum, Rhodotorula rubra and Kluyveromyces marxianus yeast have reducing effect to the mycotoxins. The TLC technique was used to determine mycotoxins concentrations in the feed wheat samples before the experiment: in the first wheat sample was detected - 670 $\mu \mathrm{g} / \mathrm{kg}$ of ZEA and $500 \mu \mathrm{g} / \mathrm{kg}$ of DON; in the second sample $-250 \mu \mathrm{g} / \mathrm{kg}$ of DON; in the third $-7 \mu \mathrm{g} / \mathrm{kg}$ of AFB1 and $700 \mu \mathrm{g} / \mathrm{kg}$ of ZEA.

The results of averages (three replicates) of feed wheat samples inoculation with Saccharomyces cerevisiae yeast suspension and Saccharomyces cerevisiae cell wall's polysaccharide with different fermentation time ar submitted in Figure 1. Saccharomyces cerevisiae yeast suspension after 30 min of fermentation reduced AFB1 by $67.1 \%(\mathrm{p}>0.05)$ and DON - $57 \%(\mathrm{p}>0.05)$, while Saccharomyces cerevisiae yeast cell wall`s polysaccharides AFB1 decreased by $77.1 \%(\mathrm{p}>0.05)$ and DON - $100 \%(\mathrm{p}<0.05)$. Saccharomyces cerevisiae yeast suspension and Saccharomyces cerevisiae yeast cell wall's polysaccharides both after $30 \mathrm{~min}$ of fermentation decreased ZEA by $54.4 \%(\mathrm{p}>0.05)$ and after $60 \mathrm{~min}$ of fermentation reduced ZEA $-100 \%(\mathrm{p}<0.05)$. 


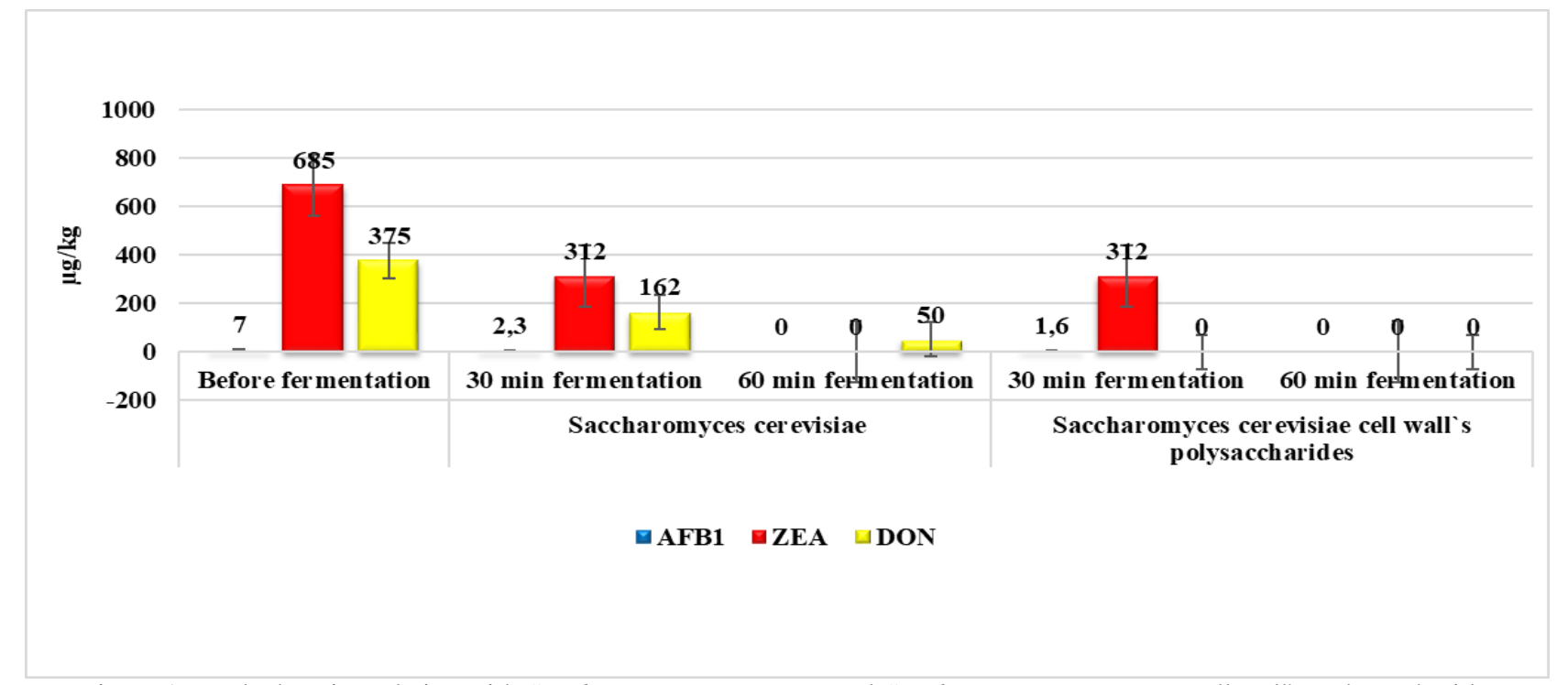

Figure 1. Feed wheat inoculation with Saccharomyces cerevisiae and Saccharomyces cerevisiae cell wall`s polysaccharide

Saccharomyces cerevisiae yeast suspension after 60 min reduced AFB1 and ZEA by $100 \%(\mathrm{p}<0.05)$ and DON up to $87 \%$ ( $\mathrm{p}<0.05)$. Saccharomyces cerevisiae yeast cell wall`s polysaccharides decreased the concentrations of AFB1 $(\mathrm{p}>0.05)$, DON $(\mathrm{p}<0.05)$ and ZEA $(\mathrm{p}<0.05)$ during the test better than Saccharomyces cerevisiae yeast suspension, and after 60 min exposure polysaccharides reduced all mycotoxins by $100 \%(\mathrm{p}<0.05)$.

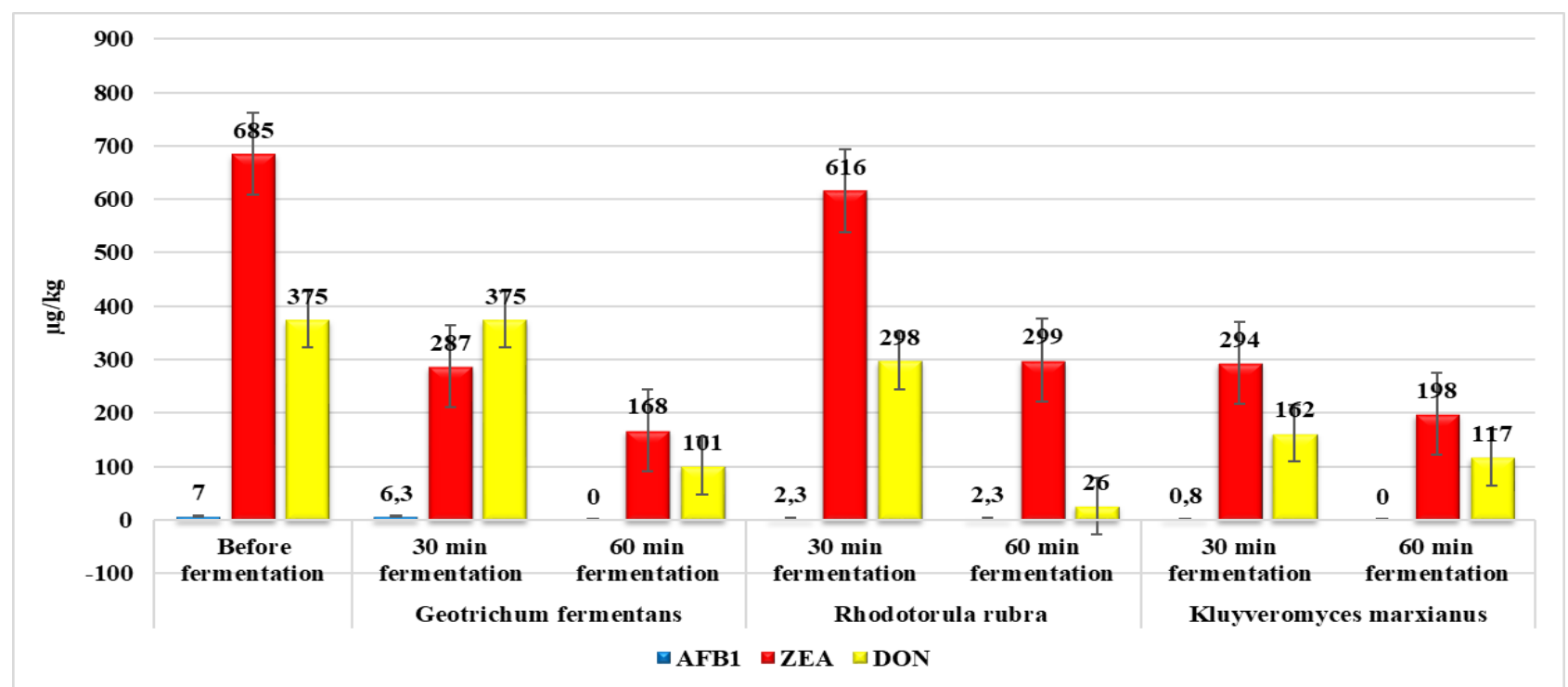

Figure 2. Feed wheat inoculation with Geotrichum fermentans, Rhodotorula rubra and Kluyveromyces marxianus yeast

The results of averages (three replicates) of feed wheat samples inoculation with Geotrichum fermentans, Rhodotorula rubra and Kluyveromyces marxianus yeast suspensions with different fermentation time are submitted in Figure 2 . After 60 min of fermentation AFB1 concentration in feed wheat samples significantly reduced by Geotrichum fermentans and Kluyveromyces marxianus yeast cell suspensions - AFB1 concentration was below detection limit ( $\mathrm{p}<0.05)$.

Geotrichum fermentans and Kluyveromyces marxianus yeast cell suspension significantly decreased ZEA concentration in feed wheat samples after $60 \mathrm{~min}$ of fermentation. Geotrichum fermentans yeast suspension ZEA concentration reduced by $75.4 \%(\mathrm{p}>0.05)$ and Kluyveromyces marxianus $-71.1 \%(\mathrm{p}>0.05)$.

DON concentration after $60 \mathrm{~min}$ of feed wheat fermentation with Rhodotorula rubra yeast cell suspension decreased by $93.1 \%(\mathrm{p}<0.05)$.

\section{CONCLUSIONS AND DISCUSSION}

Our data indicate that Saccharomyces cerevisiae yeast $10^{4}$ cell $\mathrm{ml}^{-1}$ suspension, a mixture of these yeast cell wall's polysaccharides and Geotrichum fermentans, Rhodotorula rubra and Kluyveromyces marxianus yeast suspensions had reducing effect on the mycotoxins concentrations in feed wheat.

Comparing Saccharomyces cerevisiae yeast $10^{4} \mathrm{cell} \mathrm{ml}^{-1}$ suspension and cell wall's polysaccharides was observed, that cell wall's polysaccharides showed the strongest reducing effect on the mycotoxins concentrations. Within 60 min 
fermentation $1.5 \mathrm{ml}$ polysaccharides $100 \%$ reduced concentrations of AFB1, DON, and ZEA. It can be assumed that these differences are caused by glycoproteins and lipids removed from the yeast cell walls. In addition, our study found that 60 min wheat exposure to Saccharomyces cerevisiae polysaccharides was more effective than 30 min. of fermentation, and similar dependence was also observed by Aazami et al. (2018). In the above-mentioned study, was found that purified polysaccharide reduces AFB1 concentrations more than 2 fold than the untreated cell wall's of Saccharomyces cerevisiae and based on the results of our study, has been found that Saccharomyces cerevisiae cell wall polysaccharides efficacy were 1.4 times higher.

Also, Repečkienè et al. (2013) analysed the use of yeast $10^{4}$ cells $\mathrm{ml}^{-1}$ suspension for mycotoxins concentrations reduction. Comparing the results of their and our research, the most pronounced difference is observed in the decrease of ZEA concentration. In our study, the effect of Saccharomyces cerevisiae yeast suspension (after 60 min of fermentation), ZEA on average decreased by $69 \%(\mathrm{p}>0.05)$ in wheat samples, and they found that yeast reduced the ZEA by $87 \%$, but the effect of fermentation duration has not been analysed.

During the experiment also has been observed from various vegetable substrates extracted Geotrichum fermentans, Rhodotorula rubra and Kluyveromyces marxianus yeast effect on mycotoxins concentrations. According to scientific literature, from various vegetable substrates isolated yeast the efficiency of mycotoxins detoxification is uneven, which may be due to morphological features of the yeast cell wall, enzyme systems activity and interactions with mycotoxins, leading to metabolic changes (Jakopovic et al., 2018). Repečkienè et al. (2013) have found that Geotrichum fermentans and Kluyveromyces marxianus reduces aflatoxins by $100 \%$, and in our study, after 60 min duration of fermentation was also observed at $100 \%(\mathrm{p}<0.05)$ absorption of AFB1 concentration with this yeast. However, the results are different in ZEA and DON concentrations. In our study was found that after 60 min of fermentation ZEA concentration with Kluyveromyces marxianus and Geotrichum fermentans yeast decreased up to $81 \%(\mathrm{p}<0.05)$ and the study said that after this time yeast activity the ZEA concentration is below the detection limit. Also, comparing the effect on DON concentration, Repečkiene et al. (2013) found that $7 \%$ more DON is absorbed by Kluyveromyces marxian than Geotrichum fermentans and our study found that DON was more effectively reduced by the yeast of Geotrichum fermentans. Based on the results of the mycotoxicological study, Rhodotorula rubra yeast is useful for reducing the concentration of DON after 60 min. of fermentation, as absorption is $90-100 \%$.

Fermentation time is a significant factor in feed wheat inoculation with yeast suspensions and cell wall's polysaccharides, to reduce the amount of mycotoxins. The best results were found after 60 min feed wheat fermentation with Saccharomyces cerevisiae, Geotrichum fermentans, Rhodotorula rubra and Kluyveromyces marxianus yeast suspensions and Saccharomyces cerevisiae yeast cell wall's polysaccharides. Our study research shows that after 60 min of feed wheat fermentation with Saccharomyces cerevisiae yeast suspension AFB1, DON and ZEA concentrations decreased better than after 30 min of fermentation. It was found that the best AFB1 and ZEA reducing effect in feed wheat was after 60 min of fermentation with Geotrichum fermentans and Kluyveromyces marxianus yeast cells suspensions. DON concentration best reduced Rhodotorula rubra yeast cells suspension in feed wheat samples after 60 min of fermentation.

Saccharomyces cerevisiae cell wall's polysaccharides reduced AFB1 ( $>0.05)$, DON $(p<0.05)$ and ZEA $(p<0.05)$ mycotoxins concentrations by $100 \%(\mathrm{p}<0.05)$ in feed wheat after $60 \mathrm{~min}$ of fermentation and it was more effectively than the Saccharomyces cerevisiae yeast $10^{4}$ cells $\mathrm{ml}^{-1}$ suspension.

Based on the results of the obtained research studies it was found that Saccharomyces cerevisiae yeast $10^{4}$ cells` $\mathrm{ml}^{-1}$ suspension, Saccharomyces cerevisiae cell wall's polysaccharides and from the various vegetable substrates extracted Geotrichum fermentans, Rhodotorula rubra and Kluyveromyces marxianus yeast suspensions can be used to reduce mycotoxins in feed wheat, after more detailed studies with fermentation duration, different yeast species and cellular concentrations.

\section{REFERENCES}

1. Aazami M. H., Nasri M. H. F., Mojtahedi M., Mohammadi S. R. 2018. In vitro aflatoxin B binding by the cell wall and ( $\rightarrow 3$ ) $\beta-\mathrm{D}$ - Glucan of baker's yeast. Journal of Food Protection, Vol. 81, Iss. 4, pp. 670-676. https://doi.org/10.4315/0362-028X.JFP$\underline{17-412}$

2. Asghar,M. A., Ahmed A., Iqbal J., Zahir E., Nauman,H. 2016. Fungal flora and aflatoxin contamination in Pakistani wheat kernels (Triticum aestivum L.) and their attribution in seed germination. Journal of Food and Drug Analysis, Vol. 24, Iss. 3, pp. $635-643$. https://doi.org/10.1016/j.jfda.2016.02.001

3. Bakutis B., Baliukonienė V., Paškevičius A. 2005. Use of biological method for detoxification of mycotoxins. Botanica Lithuanica, Supp. 7, pp. 123-129.

4. Beukes I., Rose L. J., Johannes van Coller G., Viljoen A. 2018. Disease development and mycotoxin production by the Fusarium graminearum species complex associated with South African maize and wheat. European Journal of Plant Pathology, Vol. 150, Iss. 4, pp. 893-910. https://doi.org/10.1007/s10658-017-1331-5

5. Bol E. K., Araujo L., Veras F. F., Welke J. E. 2016. Estimated exposure to zearalenone, ochratoxin A and aflatoxin B1 through the consume of bakery products and pasta considering effects of food processing. Food and Chemical Toxicology, Vol. 89, pp. 85-91. https://doi.org/10.1016/j.fct.2016.01.013

6. Dallies N., Francois_J., Paquuet V. 1998. A new method for quantitative determination of polysaccharides in the yeast cell wall. Application to the cell wall defective mutants of Saccharomyces cerevisiae. Yeast, Vol.14, Iss. 14, pp. $1297-1306$. https://doi.org/10.1002/(SICI)1097-0061(1998100)14:14<1297::AID-YEA310>3.0.CO;2-L 
7. FAO Food outlook. Biannual report on global food markets. 2019. Available at http://www.fao.org/3/CA2320EN/ca2320en.pdf (accessed on 27/08/2019)

8. Jakopovic Ž., Čiča K. H., Mrvčic J., Pucic I., Čanak I., Frece J., Pleadin J., Stanzer D., Zjalic S., Markovet K. 2018. Properties and fermentation activity of industrial yeasts Saccharomyces cerevisiae, S. uvarum, Candida utilis and Kluyveromyces marxianus exposed to $\mathrm{AFB}_{1}$, OTA and ZEA. Food Technology and Biotechnology, Vol. 56, No. 2, pp. $208-217$. https://doi.org/10.17113/ftb.56.02.18.5582

9. Mankevičienė A., Butkutė B., Dabkevičius Z. 2011. Peculiarities of cereal grain co - contamination with Fusarium mycotoxins. Agriculture, Vol. 98, No. 4, pp. 415-420.

10. Razzazi-Fazeli E., Rabus B., Cecon B., Bohm J. 2002. S imultaneous quantification of A-trichothecene mycotoxins in grains using liquid chromatography-atmospheric pressure chemical ionisation mass spectrometry. Journal of Chromatography A, Vol. 968 , Iss. 1-2, pp. 129-142. https://doi.org/10.1016/S0021-9673(02)00957-3

11. Repečkienė J., Levinskaitė L., Paškevičius A., Raudonienè, V. 2013. Toxin - producing fungi on feed grains and application of yeasts for their detoxification. Polish Journal of VeterinarySciences, Vol. 16, Iss. 2, pp. 391-393. https://doi.org/10.2478/pjvs$\underline{2013-0054}$

12. Samson,R. A., van Reenen-Hoekstra,E. S. 1988. Introduction to food - borne fungi. Edit 3, p. 299.

13. Stanciu O., Juan C., Miere D., Loghin F., Manes J. 2017. Occurence and co-occurrence of Fusarium mycotoxins in wheat grains and wheat flour from Romania. Food Control, Vol. 73, Part B, pp. 147-155. https://doi.org/10.1016/j.foodcont.2016.07.042

14. Wu L., Liao P., He L., Ren W., Yi, J., Duan J. 2015. Growth performance, serum biochemical profile, jejunal morphology, and the expression of nutrients transporter genes in deoxynivalenol (DON)- challenged growing pigs. BMC Veterinary Research, Vol. 11, No. 144, pp. 1-10. https://doi.org/10.1186/s12917-015-0449-y 